\title{
EDUCACIÓN, IGUALDAD Y CIUDADANÍA: APUNTES SOBRE EL TRIÁNGULO DEMOCRÁTICO DEL PACTO CONSTITUCIONAL
}

Education, equality and citizenship: notes on the democratic triangle of the constitutional pact

\author{
OCTAVIO SALAZAR BENÍTEZ ${ }^{1}$ \\ Universidad de Córdoba \\ octavio@uco.es
}

Cómo citar/Citation

Salazar Benítez, O. (2021).

Educación, igualdad y ciudadanía: apuntes sobre el triángulo democrático del pacto constitucional.

lgualdadES, 4, 219-237.

doi: https://doi.org/10.18042/cepc/lgdES.4.07

(Recepción: 08/02/2021; aceptación tras revisión: 19/04/2021; publicación: 30/06/2021)

\section{Resumen}

El derecho a la educación, desde una perspectiva constitucional, no puede entenderse solo como un derecho social. Se trata de un derecho de carácter político que desempeña un papel esencial en el ejercicio de la ciudadanía. De ahí el compromiso que el sistema educativo ha de tener en la remoción de todos los obstáculos que impiden la igualdad real. Es decir, una escuela democrática ha de ser necesariamente inclusiva y ha de ser una institución viva y abierta a las demandas de una sociedad cada vez más compleja y plural.

1 Este artículo ha sido redactado en el marco del proyecto de investigación RTI2018100669-B-100 «Generando una interpretación del Derecho en clave de igualdad de género», enmarcado en el Programa Estatal de $\mathrm{I}+\mathrm{D}+\mathrm{i}$ Orientada a los Retos de la Sociedad, Ministerio de Ciencia e Innovación (2019-2021) 


\section{Palabras clave}

Educación; igualdad; diferencias; ciudadanía; inclusiva.

\section{Abstract}

The right to education, from a constitutional perspective, cannot be understood only as a social right. It is a political right that plays an essential role in the exercise of citizenship. Hence the commitment that the educational system must have in removing all obstacles that impede real equality. In other words, a democratic school must necessarily be inclusive and must be a living institution open to the demands of an increasingly complex and plural society.

\section{Keywords}

Education; equality; differences; citizenship; inclusive. 


\section{SUMARIO}

UNA CUESTIÓN DE PODER Y CIUDADANÍA: 1. El eterno debate. 2. La rebelión de las Sofías. II. EL COMPROMISO IGUALITARIO DE LA ESCUELA DEMOCRÁTICA: 1. Educación e igualdad sustancial. 2. El compromiso educativo con la igualdad de mujeres y hombres. III. LA EDUCACIÓN INCLUSIVA COMO PRESUPUESTO DE UNA SOCIEDAD DE EQUIVALENTES. IV. BIBLIOGRAFÍA.

\section{UNA CUESTIÓN DE PODER Y CIUDADANÍA}

\section{EL ETERNO DEBATE}

Hablar de educación e igualdad puede resultar hasta redundante cuando lo hacemos desde una perspectiva democrática, en el sentido que la educación, en términos constitucionales, solo puede entenderse de, desde y para la igualdad. Y ello no solo porque estemos hablando de un derecho social que reclama la intervención de los poderes públicos para garantizarlo a todos y a todas por igual, sino también porque estamos ante un derecho político en el sentido de que es una pieza esencial para el ejercicio de la ciudadanía (Pérez, 2010: 412). Si ser ciudadano o ciudadana implica un determinado estatus jurídico, pero también, y, sobre todo, la posibilidad de tener voz y poder en los espacios compartidos, ejercer un fragmento de soberanía, el derecho a la educación es una pieza esencial en la configuración y en el ejercicio de la democracia ${ }^{2}$. Hasta el punto de que no sería osado medir la calidad de un sistema democrático en función de la calidad de su educación, evaluada esta no solo desde el punto de vista de los resultados estrictamente académicos y de la mera transmisión de conocimientos, sino de su capacidad para integrar a los individuos en la sociedad, de su acierto en la consagración de una ética compartida y de su papel en el libre y pleno desarrollo de la personalidad. De alguna manera, y más allá de la confrontación partidista que ha dominado los debates sobre la educación en nuestro país en las últimas

2 «El hilo conductor del art. 27 es la educación, no la enseñanza, pues solo la educación como ciudadanos, en tanto resultado global de las instrumentales enseñanzas recibidas, puede estar al servicio de la democracia mediante su orientación a unas finalidades constitucional-democráticas» (Aláez, 2009b: 7). 
décadas (Vidal, 2017), las grandes cuestiones que han generado controversia en torno a este derecho fundamental y a la libertad de enseñanza que en muchos casos tensiona con él, tienen que ver con diferentes maneras de entender justamente ese papel múltiple y crucial de la escuela. Es decir, los grandes debates sobre la educación en nuestro país han sido debates sobre el poder y la ciudadanía. Recordemos, sin ánimo de ser exhaustivos, las controversias generadas por la peculiar división entre enseñanza pública, privada y concertada; la cuestión siempre mal resuelta de la presencia de la(s) religión(es) en la enseñanza obligatoria; el conflicto político generado por la convivencia de lenguas distintas en determinados territorios o una de las grandes cuestiones por resolver y que no es otra que la segregación por diferentes motivos y, en consecuencia, las carencias inclusivas de nuestro modelo educativo ${ }^{3}$. La contestación generada hace unos años hacia la asignatura Educación para la Ciudadanía (Salazar, 2010: $363-444)^{4}$, y el consiguiente debate sobre el reconocimiento o no de un derecho

3 Son los debates que han centrado, en buena medida, la polémica en torno a la recientemente aprobada Ley Orgánica 3/2020, de 29 de diciembre, por la que se modifica la Ley Orgánica 2/2006, de 3 de mayo, de Educación. Recordemos el debate político que han generado cuestiones como la no financiación pública de las escuelas que segreguen por sexos, la eliminación del castellano como lengua vehicular en los territorios bilingües, la exclusión de la religión en cuanto asignatura a tener en cuenta para obtener la media y para acceder a becas, o la apuesta por una educación inclusiva para el alumnado con necesidades especiales.

4 Una asignatura que, recordemos, fue introducida por la LO 2/2006 (arts. 18.3 y 24.3) y sobre cuya legitimidad se pronunció el Tribunal Supremo en las sentencias 340,341 y 342, de 11 de febrero de 2009. De manera esquemática, y tal y como los recoge la STS de 12 de noviembre de 2012, dichas sentencias concluyeron que: (1..$\left.^{\circ}\right)$ la Constitución no reconoce un derecho general a la objeción de conciencia, sino solamente respecto del deber de prestar el servicio militar, y la jurisprudencia constitucional lo ha reconocido, también, al personal sanitario que debe intervenir en la práctica del aborto en los supuestos en que cabe legalmente; $\left(2 .^{\circ}\right)$ en consecuencia, de los arts. 16.1 y 27.3 de la Constitución no resulta el derecho de los padres a que, por motivos de conciencia, sus hijos sean eximidos de cursar determinadas materias $\mathrm{y}$, en particular, la controvertida; (3. ${ }^{\circ}$ ) el contenido asignado por las normas a las asignaturas conocidas bajo la denominación común de Educación para la Ciudadanía no supone adoctrinamiento lesivo de los derechos fundamentales reconocidos en los arts. 16 y 27 de la Constitución; (4. ${ }^{\circ}$ ) tales disciplinas escolares no descansan en concepciones relativistas ni asumen una posición respecto al género distinta de la que ya acoge el ordenamiento jurídico; $\left(5 .^{\circ}\right)$ tienen un profundo sentido moral, pues pretenden inculcar a los alumnos los valores sobre los que descansan el orden político y la paz social, valores que asume la Constitución y parten del reconocimiento de la dignidad de la persona; (6. $)$ el art. 27.2 de la Constitución obliga a los poderes 
a la objeción de conciencia por parte de padres y madres a dicha materia, es el ejemplo más evidente de cómo el carácter irremediablemente político de la educación genera tensiones ${ }^{5}$. Algunas de ellas, a mi parecer, y en el caso concreto de nuestro sistema constitucional, derivadas de las mismas imperfecciones de un art. 27 en el que se trató de hacer convivir principios contrapuestos o como mínimo poco amistosos, empezando por el doble eje derecho a la educación/ libertad de enseñanza y terminando por la más que discutible inserción del derecho de los padres y las madres a elegir para sus hijos e hijas la educación que esté más acorde con sus principios morales. Una proclamación que sería absolutamente incompatible, a mi parecer, con un Estado laico, y que, claro está, se acomoda a la ambigüedad problemática del art. 16.3 CE.

\section{LA REBELIÓN DE LAS SOFÍAS}

La dimensión política de la educación se detecta también, en estrecha relación con el principio de igualdad, a través de la historia de cómo determinados sectores han tenido que luchar en un primer momento por su incorporación a las oportunidades educativas y, posteriormente, por la superación de obstáculos que, más allá de la igualdad formal plasmada en las leyes, siguen dificultando en la práctica que determinados individuos y grupos puedan desarrollar de manera plena su personalidad. El ejemplo más flagrante es el de las mujeres, en cuanto que, como mitad de la población, y desde una clave democrática mitad de la ciudadanía, tuvieron que pelear por su reconocimiento como iguales en el disfrute de este derecho (Nuño, 2020). Es justamente la exclusión de las mujeres del modelo educativo diseñado para el hombre ciudadano —el Emilio de Rousseau- uno de los argumentos esenciales de los primeros momentos del pensamiento y de la vindicación feminista. Ahí está, para recordárnoslo, la Vindicación de los derechos de la mujer, en la que Mary Wollstonecraft exige ser tratada como un ser racional y, por lo tanto, sin más privilegios ni menos derechos que los varones. De ahí su crítica a la Sofía de Rousseau, educada para ser la esposa y madre sumisa, en

públicos a asegurar la enseñanza de esos fundamentos y limita el derecho reconocido a los padres por el art. 27.3; (7..$^{\circ}$ la jurisprudencia del Tribunal Europeo de Derechos Humanos, expresada en las sentencias dictadas en los asuntos Folguero contra Noruega y Hasan y Zengin contra Turquia, no conduce a conclusiones distintas porque se refiere a un supuesto diferente: la enseñanza obligatoria de una determinada religión; (8. $\left.{ }^{\circ}\right)$ la forma en que se imparta la materia y los materiales que se utilicen para ello han de ser respetuosos con el principio de neutralidad ideológica cuando afronten cuestiones controvertidas en la sociedad española.

5 A la polémica sobre Educación para la Ciudadanía podemos sumar la más reciente sobre el llamado «pin parental» (Álvarez, 2010: 180-186). 
lo que podemos considerar uno de los pilares esenciales de lo que siglos más tarde el feminismo conceptualizaría como contrato sexual. Una vindicación, la de Wollstonecraft, que ya en 1674 había planteado Poullain de la Barre en su De la educación de las damas, como un siglo después lo subrayaría Condorcet en Sobre la admisión de las mujeres al derecho de ciudadanía, en el que contundente afirmaba: «Se dice que responden más a los sentimientos que a la razón. Eso es cierto, pero no demuestra nada: no es la naturaleza, sino la educación la que le lleva a la mujer a esa diferencia social $»^{6}$. Por ello, no deja de ser incluso alarmante que en pleno siglo xxI, y como más adelante concretaremos, uno de los debates que algunos sectores consideran todavía no cerrado sea el relacionado con el amparo constitucional de la educación diferenciada por razón de sexo. Un debate que, a su vez, hay que situar en un contexto en el que, pese a todos los avances vividos en los cuarenta años de democracia, aún continúa siendo deudor en muchos casos de una cultura machista, del peso de sesgos y estereotipos ${ }^{7}$, así como de una escasa incorporación a los contenidos educativos de la perspectiva de género. Una carencia que resulta especialmente censurable en los grados universitarios, dado su papel en la formación de los y las futuras profesionales que, desde diferentes ámbitos - pensemos, sin ir más lejos, en el caso del derecho (Saldaña, 2010) - van a tener un papel decisivo en una sociedad que permanentemente tiene que actualizar los valores constitucionales.

\section{EL COMPROMISO IGUALITARIO DE LA ESCUELA DEMOCRÁTICA}

\section{EDUCACIÓN E IGUALDAD SUSTANCIAL}

Si analizamos qué situaciones son las que hoy continúan generando obstáculos en el acceso pleno a la enseñanza es evidente la conexión que existe entre la efectividad del derecho a la educación y el sentido que tiene la

6 Recordemos que el debate que trata de zanjar Condorcet ha seguido abierto durante siglos desde el momento en que determinados sectores de la comunidad científica han mantenido y mantiene que hay diferencias cerebrales y cognitivas en niños y niñas, lo cual legitimaría la necesidad de una educación segregada. Desde la neurología, sin embargo, no parece haber pruebas suficientes de dicha diferenciación, sino más bien de la plasticidad del cerebro a lo largo de nuestra vida y, por tanto, de la incidencia que, por ejemplo, una sociedad sexista puede tener en la transmisión de estereotipos de género en niños y niñas (Rippon, 2020).

7 Recordemos que, como explica Fernando Rey (2019: 53), «la discriminación es una conducta (positiva u omisiva), cuyo equipaje ideológico es el prejuicio que, a su vez, se funda en un estereotipo». 
prohibición de discriminaciones que marca el art. $14 \mathrm{CE}$, interpretada siempre en conexión con el mandato de remoción de obstáculos del art. 9.2 CE8 Pensemos, como bien ha analizado recientemente Fernando Rey (2021), en la situación de las personas con discapacidad, en la de los menores migrantes, en los niños y en las niñas gitanas o en los hijos y en las hijas de las familias con menos recursos económicos. Si, como hemos señalado, la educación es un derecho esencial para convertir al individuo en ciudadano y si, gracias a ella, cualquier persona dispone de más recursos para poder desarrollar libremente su personalidad y construir en definitiva su proyecto de vida, parece obvio, o debería serlo, la centralidad de la enseñanza pública en la superación de los obstáculos que impiden el disfrute de una igual ciudadanía ${ }^{9}$ Y Y digo bien pública porque entiendo que es la única con capacidad para actuar con una lógica redistributiva de recursos y oportunidades. De esta manera, el lazo íntimo entre la igualdad —entendida en un sentido complejo y superador de la ya estrecha dicotomía formal/material - y la educación es, o debería ser, más que evidente. Por lo tanto, y de la misma manera que la igualdad, y la

8 Esta íntima conexión es fácil de detectar en los nuevos apdos. que la LO 3/20 ha incluido en el art. 1 LO 2/2006: «a bis) La calidad de la educación para todo el alumnado, sin que exista discriminación alguna por razón de nacimiento, sexo, origen racial, étnico o geográfico, discapacidad, edad, enfermedad, religión o creencias, orientación sexual o identidad sexual o cualquier otra condición o circunstancia personal o social»; «b) La equidad, que garantice la igualdad de oportunidades para el pleno desarrollo de la personalidad a través de la educación, la inclusión educativa, la igualdad de derechos y oportunidades, también entre mujeres y hombres, que ayuden a superar cualquier discriminación y la accesibilidad universal a la educación, y que actúe como elemento compensador de las desigualdades personales, culturales, económicas y sociales, con especial atención a las que se deriven de cualquier tipo de discapacidad, de acuerdo con lo establecido en la Convención sobre los Derechos de las Personas con Discapacidad, ratificada en 2008, por España»; «k) La educación para la convivencia, el respeto, la prevención de conflictos y la resolución pacífica de los mismos, así como para la no violencia en todos los ámbitos de la vida personal, familiar y social, y en especial en el del acoso escolar y ciberacoso con el fin de ayudar al alumnado a reconocer toda forma de maltrato, abuso sexual, violencia o discriminación y reaccionar frente a ella»; «l) El desarrollo de la igualdad de derechos, deberes y oportunidades, el respeto a la diversidad afectivo-sexual y familiar, el fomento de la igualdad efectiva de mujeres y hombres a través de la consideración del régimen de la coeducación de niños y niñas, la educación afectivo-sexual, adaptada al nivel madurativo, y la prevención de la violencia de género, así como el fomento del espíritu crítico y la ciudadanía activa».

9 «Queremos educación pública igual porque esa es la forma de ser menos subalternos, pero también porque es un camino hacia la mejor educación universal posible» (Rendueles, 2020: 295). 
correlativa no discriminación, es el fundamento y la condición previa de todos los derechos, la educación se convierte, desde esta perspectiva, también en el presupuesto sin el que no resulta posible el ejercicio pleno de los derechos fundamentales, tales como la libertad de conciencia, la libertad de expresión o la participación política. De la misma manera que solo desde una educación comprometida con los derechos (art. 27.2 CE) es posible garantizar un marco de convivencia en el que habiten en armonía la igualdad y el pluralismo. Es decir, solo desde ese modelo es posible lo que Amy Guttman (2001: 66) denomina «reproducción social consciente». En consecuencia, la ubicación constitucional del derecho fundamental a la educación transcendería el mismo art. 27, dada su conexión con los arts. 14 y $9.2^{10}$, pero también con los presupuestos axiológicos que subraya el art. 10 y con la misma definición del Estado y de los valores superiores del ordenamiento (art. 1) ${ }^{11}$. Es decir,

10 «Sin educación tampoco puede haber igualdad, real y efectiva (art. 9.2 CE), de las personas. El derecho de educación remite al Estado social, a la igualdad de oportunidades, a la prestación equitativa de los servicios públicos. El derecho de educación es, desde este punto de vista, uno de los más relevantes derechos sociales y tiene un intenso contenido prestacional [...]» (Rey, 2021: 12).

11 En este sentido, conviene recordar lo expresado en el voto particular que el magistrado Juan Antonio Xiol i Ríos formuló en la STC 31/2018: «Creo que la prohibición de la discriminación merece algo más que una ritual mención de su interdicción. La comprensión de esta prohibición hace preciso profundizar en el significado que tiene en los Estados democráticos avanzados. El derecho antidiscriminatorio no es una medida de la calidad democrática. Es una condición esencial de la democracia misma. La prohibición de determinados motivos de discriminación está íntimamente vinculada con la dignidad humana (art. 10.1 CE), los valores superiores de la igualdad y del pluralismo político como fundamento del ordenamiento jurídico de un Estado social y democrático de Derecho (art. 1.2 CE) y el mandato dirigido a los poderes públicos de promover las condiciones para que la igualdad del individuo y de los grupos en que se integra sean reales y efectivas, removiendo los obstáculos que impidan o dificulten su plenitud (art. 9.2 CE). La selección de esos motivos no resulta azarosa. Es el producto fenomenológico — iba a decir trágico — del devenir histórico y la lucha contra la prevalencia en determinados momentos históricos de ideologías y paradigmas que han justificado un tratamiento diferenciado de grupos sociales con fundamento en esos motivos. La raza o grupo étnico, la religión, la opinión política, el origen nacional, el sexo — incluyendo sus modalidades de identidad y orientación sexual—o las capacidades físicas e intelectivas diferenciadas, solo por citar alguno de ellos, han sido - y son todavía hoy en muchos ámbitos- elementos frecuentemente utilizados para implantar visiones excluyentes, supremacistas, segregadoras o justificadoras de situaciones de violencia o acoso discriminatorio. El carácter especialmente odioso de cualquiera de estas formas de discriminación basadas en esos y otros motivos es lo 
la conexión entre educación y ciudadanía se produce a través de la igualdad sustancial, entendida esta como «un elemento definidor de la noción de ciudadanía» (STC 12/2008, FJ 5). De todo ello, además, podemos concluir que un sistema educativo que excluya a determinados grupos o colectivos o que no contribuya a superar los obstáculos que los mismos tienen en el disfrute pleno del derecho a la educación, acaba provocando una discriminación institucional (Rey, 2021: 41) ${ }^{12}$.

No se trata por tanto solamente de que el sistema educativo deba responder al ideario que marca el art. 27.2 CE, sino que el derecho fundamental a la educación es el cauce imprescindible para el libre - y pleno- desarrollo de la personalidad, sin el cual la dignidad no es posible y que constituye la base del orden político y de la paz social ${ }^{13}$. En consecuencia, y como advirtiera

determinante para su proscripción. A partir de ello, el derecho antidiscriminatorio ha evolucionado hasta establecer que (i) la utilización de estos motivos por el legislador resulta tan intrínsecamente sospechosa que solo muy poderosas razones vinculadas a superiores intereses pueden permitir su utilización para implantar tratos diferenciados y (ii) debe posibilitarse, con el fin de compensar situaciones históricas de prolongada discriminación, actuaciones afirmativas o positivas de carácter temporal en favor de esos grupos en desventaja tendentes a superar esa situación de postergación y alcanzar los objetivos de una real igualdad de oportunidad y trato. Por tanto, a mi juicio debe extremarse la sensibilidad para compaginar la jurisprudencia antidiscriminatoria con las exigencias de una democracia moderna europea del siglo xxI como es la española». Este es el objetivo que persigue el tratamiento que la LO 3/20 plantea del alumnado con necesidades especiales, de acuerdo con lo previsto en su DA 4.a: «Las Administraciones educativas velarán para que las decisiones de escolarización garanticen la respuesta más adecuada a las necesidades específicas de cada alumno o alumna, de acuerdo con el procedimiento que se recoge en el artículo 74 de esta Ley. El Gobierno, en colaboración con las Administraciones educativas, desarrollará un plan para que, en el plazo de diez años, de acuerdo con el artículo 24.2.e) de la Convención sobre los Derechos de las Personas con Discapacidad de Naciones Unidas y en cumplimiento del cuarto Objetivo de Desarrollo Sostenible de la Agenda 2030, los centros ordinarios cuenten con los recursos necesarios para poder atender en las mejores condiciones al alumnado con discapacidad. Las Administraciones educativas continuarán prestando el apoyo necesario a los centros de educación especial para que estos, además de escolarizar a los alumnos y alumnas que requieran una atención muy especializada, desempeñen la función de centros de referencia y apoyo para los centros ordinarios».

13 Recordemos cómo la STC 133/2010, de 2 de diciembre, dictada en relación con el deber de escolarización de los menores de entre seis y dieciséis años, señalaba que, de acuerdo con el art. 27.2 CE, la finalidad de la educación no es solo la transmisión de conocimientos, sino la aspiración a posibilitar el libre desarrollo de la personalidad y de las capacidades de los alumnos y la formación de ciudadanos responsables 
Tomás y Valiente en su voto particular a la STC 5/81, «todo ideario educativo que coarte o ponga en peligro el desarrollo pleno y libre de la personalidad de los alumnos será nulo por opuesto a la Constitución». Es decir, el objeto del derecho a la educación

está compuesto por una esfera vital que no consiste ni exclusivamente en ejercer la libertad de enseñanza, ni exclusivamente en recibir una prestación educativa, sino en la recepción de una formación cívica basada en los valores democrático-constitucionales - derecho prestacional a la educación, ideario educativo constitucional, poder estatal de organización y planificación de la enseñanza, etc.—, que no es posible sin un proceso libre de transmisión de conocimientos — libertad de enseñanza, libertad de creación de centros docentes, autonomía universitaria- (Aláez, 2009a: 35-36) ${ }^{14}$.

Desde esta perspectiva, a su vez, la educación cobra todo su vigor en cuanto herramienta que hace posible el entendimiento de la igualdad como reconocimiento de las diferencias (Ferrajoli, 2019: 14). Es justamente nuestro derecho a ser diferentes, sin que ello implique convertirnos en el otro y sin que eso afecte a nuestro estatuto de ciudadanía, el que dota de sustancia y de contenido ético a la igualdad ${ }^{15}$. De ahí también el papel crucial de la escuela en cuanto espacio de reequilibrio social y, en consecuencia, la necesidad de articular en la práctica un sistema educativo que sea lo suficientemente inclusivo en un doble sentido: a) que ningún individuo, grupo o colectivo

llamados a participar en los procesos que se desarrollan en el marco de una sociedad plural en condiciones de igualdad y tolerancia, y con pleno respeto a los derechos y libertades fundamentales del resto de sus miembros (FJ 7 a).

14 Esta formación, lógicamente, adquiere una mayor densidad de contenidos y compromiso en función del grado de madurez del alumnado, llegado por tanto a su máxima expresión en el Bachillerato, el cual «tiene como finalidad proporcionar formación, madurez intelectual y humana, conocimientos, habilidades y actitudes que permitan desarrollar funciones sociales e incorporarse a la vida activa con responsabilidad y competencia. Asimismo, esta etapa deberá permitir la adquisición y logro de las competencias indispensables para el futuro formativo y profesional y capacitar para el acceso a la educación superior» (nuevo apdo. 1 del art. 32 LO 2/2006, redactado por la LO 3/2020).

15 En esta línea, el preámbulo de la «Ley Orgánica 3/2020, de 29 de diciembre, por la que se modifica la Ley Orgánica 2/2006, de 3 de mayo, de Educación» alude expresamente a los fines de «fomentar la convivencia democrática y el respeto a las diferencias individuales, promover la solidaridad y evitar la discriminación, con el objetivo fundamental de lograr la necesaria cohesión social». 
sea excluido en el acceso, en condiciones de igualdad, al mismo ${ }^{16}$; b) que dicho sistema se convierta en la correa de transmisión principal de los valores constitucionales y sitúe en el centro de sus contenidos la formación y la sensibilización en materia de derechos humanos. Solo de esta manera podrá garantizarse la paz social o, lo que es lo mismo, la convivencia de los y las diferentes, sin que en ningún caso la diferencia se convierta en presupuesto legitimador de una "casta inferior» ${ }^{17}$. Solo mediante el factor preventivo que supone la socialización en determinados valores podrán limitarse al mínimo las prácticas discriminatorias, las que en los modernos ordenamientos penales se identifican como delitos de odio y de discriminación y, en general, cualquier praxis que ponga en peligro o atente contra la dignidad humana. Una lección que deberíamos recordar más que nunca en unos tiempos en los que con tanta frecuencia, desde el punto de vista normativo, se abusa de las disposiciones sancionadoras, al tiempo que se escatiman esfuerzos e inversiones en políticas públicas preventivas. En este sentido, no solo unas políticas públicas educativas de calidad exigen una sólida y sostenible inversión presupuestaria, sino también todas las que están dirigidas a hacer efectivo el principio de igualdad.

16 En este sentido, es significativo que la LO 3/2020 dé un nuevo título al capítulo II del título II, «Equidad y compensación de las desigualdades en educación», cuyo primer artículo, el 80, establece que «con el fin de hacer efectivo el principio de equidad en el ejercicio del derecho a la educación, las Administraciones públicas desarrollarán acciones dirigidas hacia las personas, grupos, entornos sociales y ámbitos territoriales que se encuentren en situación de vulnerabilidad socioeducativa y cultural con el objetivo de eliminar las barreras que limitan su acceso, presencia, participación o aprendizaje, asegurando con ello los ajustes razonables en función de sus necesidades individuales y prestando el apoyo necesario para fomentar su máximo desarrollo educativo y social, de manera que puedan acceder a una educación inclusiva, en igualdad de condiciones con los demás. 2. Las políticas de compensación reforzarán la acción del sistema educativo de forma que se eviten desigualdades derivadas de factores sociales, económicos, culturales, geográficos, étnicos o de otra índole».

17 «Cualquier discriminación es, en efecto, una conducta basada en un doble error fatal porque, de un lado, se funda en un prejuicio hostil contra un determinado grupo, prejuicio que no es compatible con un mínimo examen racional, y, de otro lado, atribuye a todos los miembros de ese grupo las características negativas comunes, con absoluta independencia de los méritos y la trayectoria individuales de tales miembros. Cualquier discriminación lesiona de un modo especialmente grave la dignidad humana y, al mismo tiempo, sitúa al grupo al que pertenece la persona discriminada en una situación social (y a menudo también económica y política) de subordinación. Una segregación del tipo que sea, también la escolar, convierte a un grupo social determinado en una casta inferior»(Rey, 2021: 38). 


\section{EL COMPROMISO EDUCATIVO CON LA IGUALDAD DE MUJERES $Y$ HOMBRES}

Pensemos, por ejemplo, en las importantes leyes adoptadas en nuestro país en materia de igualdad de género. Si repasamos el contenido de la LO 1/2004, de 28 de diciembre, de Medidas de Protección Integral contra la Violencia de Género, y de la LO 3/2007, de 22 de marzo, para la Igualdad Efectiva de Mujeres y Hombres (LOIEMH), más allá de las medidas concretas que se dirigen a corregir desequilibrios de género o a superar obstáculos que impiden la igual ciudadanía, ambas coinciden en el lugar central que otorgan a los compromisos educativos y socializadores. Unos contenidos en los que insisten normas internacionales como la CEDAW o el Convenio del Consejo de Europa sobre prevención y lucha contra la violencia contra las mujeres y la violencia doméstica (Estambul, 2011) ${ }^{18}$, las cuales, además de formar parte de nuestro ordenamiento jurídico, son un marco interpretativo obligatorio en materia de derechos fundamentales (art. 10.2 CE). Si a ello sumamos la rotundidad del derecho comunitario en esta materia (art. 3.2 TUE/1997, art. 8 TUE/2007) ${ }^{19}$, así como de la consolidada interpretación que de la igualdad entre hombres y mujeres se ha realizado por nuestro Tribunal Constitucional a partir de los arts. 14 y 9.2 CE, debiera ser evidente la esencialidad de dicho principio en cuanto eje vertebrador de nuestro modelo educativo ${ }^{20}$. Un

18 Los contenidos que se proyectan en el ámbito educativo son esenciales en todos los instrumentos legislativos que pretenden superar discriminaciones de determinados grupos o colectivos. Es el caso, por el ejemplo, de la prolija legislación aprobada a nivel autonómico sobre protección de derechos del colectivo LGBTI. Este compromiso es también evidente, desde una perspectiva más genérica de lo que podemos identificar como derecho antidiscriminatorio, en la Proposición de ley de igualdad de trato y para la no discriminación, presentada a finales de enero de 2021 por el Grupo Parlamentario Socialista (arts. 11 y 12). La Proposición puede consultarse en: https:// bit.ly/3h15XMq (consultada: 10-02-21)

19 Así se subraya en la ambiciosa y reciente Resolución del Parlamento Europeo, de 21 de enero de 2021, sobre la estrategia de la Unión para la igualdad de género (https:// bit.ly/3aYe7B6, consultada: 10-02-21).

20 Ese compromiso se hace explícito en la nueva redacción dada por la LO 3/20 a la disposición adicional vigésima quinta de la LO 2/06, dedicada al «Fomento de la igualdad efectiva entre hombres y mujeres»: «1. Con el fin de favorecer la igualdad de derechos y oportunidades y fomentar la igualdad efectiva entre hombres y mujeres, los centros sostenidos parcial o totalmente con fondos públicos desarrollarán el principio de coeducación en todas las etapas educativas, de conformidad con lo dispuesto por la Ley Orgánica 3/2007, de 22 de marzo, para la igualdad efectiva de mujeres y hombres, 
compromiso que alcanzó su máxima expresión a través de las obligaciones establecidas por la LOIEMH. Entre ellas, la integración del principio de igualdad en la interpretación y aplicación de las normas (art. 4) o la asunción de la transversalidad de dicho principio (art. 15), el cual debe ser asumido por todas las Administraciones públicas «de forma activa, en la adopción y ejecución de sus disposiciones normativas, en la definición y presupuestación de políticas públicas en todos los ámbitos y en el desarrollo del conjunto de todas sus actividades». De manera más específica, dicha ley obliga a que el principio de igualdad se integre en todas las etapas del sistema educativo (arts. 23, 24 y 25). Difícilmente la escuela diferenciada puede revertir en el desarrollo pleno de la personalidad de los niños y las niñas que han de convivir bajo un "contrato social» que parta de su equivalencia como sujetos y en una sociedad en la que todavía hoy es necesario «remover» muchos obstáculos que siguen impidiendo la efectividad de dicho principio (Salazar, 2016) ${ }^{21}$. Este mismo argumento es el que nos lleva a justificar la necesidad de un modelo educativo inclusivo, de tal manera que la escuela desempeñe un papel esencial en la remoción de los obstáculos que hacen que determinadas personas, grupos

y no separarán al alumnado por su género. 2 . Con objeto de favorecer la igualdad de derechos y oportunidades y, para garantizar la efectividad del principio contenido en el apdo. 1) del artículo 1, los centros educativos incorporarán medidas para desarrollar la igualdad efectiva entre hombres y mujeres en los respectivos planes de acción tutorial y de convivencia. 3. Los centros educativos deberán necesariamente incluir y justificar en su proyecto educativo las medidas que desarrollan para favorecer y formar en igualdad en todas las etapas educativas, incluyendo la educación para la eliminación de la violencia de género, el respeto por las identidades, culturas, sexualidades y su diversidad, y la participación activa para hacer realidad la igualdad. 4. En todo caso, las Administraciones educativas impulsarán el incremento de la presencia de alumnas en estudios del ámbito de las ciencias, tecnología, ingeniería, artes y matemáticas, así como en las enseñanzas de formación profesional con menor demanda femenina. Del mismo modo, las Administraciones educativas también promoverán la presencia de alumnado masculino en aquellos estudios en los que exista de forma notoria una mayor matrícula de mujeres que de hombres. 5. Las Administraciones educativas promoverán que los currículos y los libros de texto y demás materiales educativos fomenten el igual valor de mujeres y hombres y no contengan estereotipos sexistas o discriminatorios. Asimismo, incluirán estos contenidos en los programas de formación inicial del profesorado».

21 Incluso se plantea ir más allá de la «coeducación» para implantar una «educación feminista», entendiendo por tal «aquella que, de manera intencionada y emancipadora, tiene como finalidad eliminar la discriminación por sexo y superar los roles de género, buscando el desarrollo de personas libres que trabajen de forma cooperativa en pos del bien común» (Alcalá, 2020, 89). 
o colectivos no disfruten, de hecho, de un estatus pleno de ciudadanía. Todo ello al tiempo que se mantiene atenta a la misma evolución de la sociedad, en cuanto que la escuela también ha de jugar un papel esencial en la interpretación evolutiva (STC 198/2012) del mismo sistema constitucional al hilo de los cambios sociales y culturales. Pensemos, sin ir más lejos, en cómo el sistema educativo ha tenido y tiene una singular responsabilidad en el reconocimiento de la diversidad de opciones sexuales y en la pluralidad de modelos familiares que se han ido extendiendo en las últimas décadas ${ }^{22}$.

Por todo lo señalado, resulta tan cuestionable el posicionamiento del TC en sus sentencias 31/2018 y 74/2012, en las que avala el sostén público de escuelas que diferencien al alumnado en función del sexo ${ }^{23}$. Tal y como señalan los votos particulares formulados dicha opción difícilmente encaja

22 En esta línea, la nueva redacción dada a la disposición adicional cuadragésima primera de la LO 2/2006 por la LO 3 /2020, dedicada a los «Valores que sustentan la democracia y los derechos humanos y prevención y resolución pacífica de conflictos»: «En el currículo de las diferentes etapas de la educación básica se atenderá al aprendizaje de la prevención y resolución pacífica de conflictos en todos los ámbitos de la vida personal, familiar y social, y de los valores que sustentan la democracia y los derechos humanos, que debe incluir, en todo caso, la igualdad entre mujeres y hombres, la igualdad de trato y la no discriminación, así como la prevención de la violencia de género y el acoso escolar o cualquier otra manifestación de violencia. Se recogerá asimismo el conocimiento de la historia de la democracia en España desde sus orígenes a la actualidad y su contribución al fortalecimiento de los principios y valores democráticos definidos en la Constitución española. De la misma forma, se considerará el estudio y respeto de otras culturas, particularmente la propia del pueblo gitano y la de otros grupos y colectivos, contribuyendo a la valoración de las diferencias culturales, así como el reconocimiento y la difusión de la historia y cultura de las minorías étnicas presentes en nuestro país, para promover su conocimiento y reducir estereotipos. Se atenderá también al conocimiento de hechos históricos y conflictos que han atentado gravemente contra los derechos humanos, como el Holocausto judío y la historia de lucha por los derechos de las mujeres».

El TC avaló la constitucionalidad del art. 84.3 Ley Orgánica 8/2013, de 9 de diciembre, para la mejora de la calidad educativa, en el que se preveía que «no constituye discriminación la admisión de alumnos y alumnas o la organización de la enseñanza diferenciadas por sexos, siempre que la enseñanza que impartan se desarrolle conforme a lo dispuesto en el articulo 2 de la Convención relativa a la lucha contra las discriminaciones en la esfera de la enseñanza, aprobada por la Conferencia General de la UNESCO el 14 de diciembre de 1960». Este inciso ha sido eliminado por la recientemente aprobada LO 3/2020. El pronunciamiento del TC ha dado lugar a un amplio debate entre quienes lo consideran insostenible (Rey, 2021, 106) y quienes lo interpretan como «consolidación constitucional de la educación diferenciada» (Báez, 2019). 
con el principio de igualdad y con un ideario educativo comprometido con los mandatos del art. 14 y 9.2 CE, además de con todos los compromisos internacionales ratificados por España en materia de igualdad de mujeres y hombres. Estas sentencias ponen en evidencia cómo el Tribunal Constitucional no ha integrado en su labor interpretativa la perspectiva de género (Gómez, 2019) y, en consecuencia, no valora si efectivamente la educación diferenciada contribuye, por ejemplo, a mantener los estereotipos de género o si resulta adecuada para formar a una ciudadanía, compuesta por mujeres y hombres, en el compromiso con los valores constitucionales. Es decir, tal y como explica el voto particular de Fernando Valdés,

la educación segregada por sexo priva a los alumnos y a los profesores del escenario o contexto necesarios para educar a partir de una percepción democrática de los acusados conflictos de género que en nuestra sociedad aún se mantienen, sin que, lamentablemente, los poderes públicos adopten las medidas necesarias para su prevención y consiguiente solución. Los modelos pedagógicos de la educación diferenciada, al confrontar con ese ideario educativo, se sitúan fuera del contenido esencial del derecho a la educación; o si se prefiere, de la libertad de enseñanza y de creación de centros escolares.

El pronunciamiento del TC en ese asunto, como indica el voto particular de M. ${ }^{\mathrm{a}}$ Luisa Balaguer, supone «un paso atrás en la historia, desconociendo que las diferencias de género son meramente culturales, y que no existe base científica alguna en la consideración de una diferencia biológica, capaz de sustentar las diferencias entre las mujeres y los hombres en relación con sus capacidades intelectuales». Además, desde la perspectiva más estricta del derecho antidiscriminatorio, el TC se aparta de lo que ha sido su doctrina consolidada. Como ha dicho este Tribunal en su sentencia 2/2017, de 16 de enero,

para hacer efectiva la cláusula de no discriminación por razón de sexo del artículo 14 CE, este Tribunal ha establecido un canon mucho más estricto y riguroso que el de la mera razonabilidad que, desde la perspectiva genérica del principio de igualdad, se exige para la justificación de la diferencia normativa de trato». En efecto, como ha tenido ocasión de declarar este Tribunal (SSTC 233/2007, de 5 de noviembre, FJ 5; 66/2014, de 5 de mayo, FJ 2, y 162/2016, de 3 de octubre, FJ 4), «a diferencia del principio genérico de igualdad, que no postula ni como fin ni como medio la paridad y sólo exige la razonabilidad de la diferencia normativa de trato, las prohibiciones de discriminación contenidas en el artículo $14 \mathrm{CE}$ implican un juicio de irrazonabilidad de la diferenciación establecida ex constitutione, que imponen como fin y generalmente como medio la parificación, de manera que sólo pueden ser utilizadas excepcionalmente por el legislador como criterio de diferenciación jurídica, lo que implica la necesidad de usar en el juicio de legitimidad constitucional un canon mucho más estricto, así como un mayor rigor respecto a las exigencias materiales de proporcionalidad». 
Y si los anteriores argumentos sirven para controlar el ajuste constitucional de medidas adoptadas en el ámbito laboral, con más razón deben servir para asegurar que niños y niñas disfruten del derecho a la educación obligatoria, de que son titulares, sin que exista sombra de duda sobre el respeto, en el seno del sistema educativo, y concretamente en los centros escolares que imparten la enseñanza que reciben, al principio de no discriminación por razón de sexo. Por lo tanto, es más que evidente que «la separación de niños y niñas es, objetivamente, una brecha de inclusión» (Rey, 2019, 196).

\section{LA EDUCACIÓN INCLUSIVA COMO PRESUPUESTO DE UNA SOCIEDAD DE EQUIVALENTES}

Todas estas cuestiones estuvieron presentes en las distintas mesas temáticas que abordaron el derecho a la educación en el XVIII Congreso de la Asociación de Constitucionalistas de España, celebrado de manera virtual los días 11 y 12 de marzo de 2021, aunque lógicamente centraron el debate previsto en la dedicada a educación e igualdad ${ }^{24}$. Un debate más que oportuno por varias razones. De un lado, la reciente aprobación de la conocida como ley Celá, otra norma educativa aprobada sin consenso de las grupos parlamentarios y con un intenso debate en torno a cuestiones que, en definitiva, vienen a reproducir las que desde hace años protagonizan los enfrentamientos políticos en torno al art. $27 \mathrm{CE}$. De otro, la centralidad que durante la pandemia, y muy en especial durante los períodos de confinamiento, ha ocupado la enseñanza, en un contexto más amplio vinculado con las necesidades de conciliación de la vida familiar y laboral, además de por supuesto con las injustas brechas que ha generado la sustitución de la enseñanza presencial por la telemática. Todo ello, recordemos, en el marco de un modelo constitucional de enseñanza en el que no cabe lo que se conoce como homeschooling (STC 133/2010). La gran paradoja que estamos viviendo es que, por la fuerza mayor de la pandemia, hemos convertido, aunque haya sido temporal y excepcionalmente, la enseñanza en casa en la modalidad única. Y, entre otros interrogantes, esta opción nos hace plantearnos hasta qué punto la enseñanza on line contribuye a «la preparación para el ejercicio de la ciudadanía, para la inserción en la sociedad que le rodea y para la participación activa en la vida económica, social y cultural, con actitud crítica y responsable y con capacidad

24 Es curioso, sin embargo, que el título del Congreso obvie cualquier referencia a la igualdad y opte por «Educación y libertades en la democracia constitucional» (https:// bit.ly/3aXv7Yw, consultada: 11-02-21) 
de adaptación a las situaciones cambiantes de la sociedad del conocimiento» (apdo. k del art. 2 LO 2/2006, introducido por la LO 3/20).

Esta situación ha servido, entre otras cosas, para poner de manifiesto muchas de las debilidades de nuestro sistema educativo, tales como la prolongada carencia de recursos materiales y humanos, la descoordinación entre las distintas Administraciones o la escasa adaptación de los centros y del mismo personal docente a una realidad que, con independencia de la situación excepcional vivida en el 2020, reclama otras estrategias de aprendizaje, otros medios e incluso un lenguaje distinto: el propio de una era no solo de imperio de lo audiovisual, sino de tecnologías que están provocando un cambio de paradigma en el conocimiento e, incluso, en la dimensión relacional de los seres humanos ${ }^{25}$. Este conjunto de realidades, insisto, más allá de la excepcionalidad provocada por la crisis sanitaria, nos alerta a su vez de cómo la desigualdad creciente en nuestras sociedades globales, y agravada por las sucesivas crisis económicas vividas en estos años ${ }^{26}$, coloca de nuevo a la educación pública en una compleja tesitura

25 Así lo evidencia el preámbulo de la LO 3/2020: «Asimismo, el uso generalizado de las tecnologías de información y comunicación en múltiples aspectos de la vida cotidiana ha acelerado cambios profundos en la comprensión de la realidad y en la manera de comprometerse y participar en ella, en las capacidades para construir la propia personalidad y aprender a lo largo de la vida, en la cultura y en la convivencia democráticas, entre otros. Este cambio de enfoque requiere de una comprensión integral del impacto personal y social de la tecnología, de cómo este impacto es diferente en las mujeres y los hombres y una reflexión ética acerca de la relación entre tecnologías, personas, economía y medioambiente, que se desarrolle tanto en la competencia digital del alumnado como en la competencia digital docente. En consecuencia, se hace necesario que el sistema educativo dé respuesta a esta realidad social e incluya un enfoque de la competencia digital más moderno y amplio, acorde con las recomendaciones europeas relativas a las competencias clave para el aprendizaje permanente.»E insiste: "la Ley insiste en la necesidad de tener en cuenta el cambio digital que se está produciendo en nuestras sociedades y que forzosamente afecta a la actividad educativa. El desarrollo de la competencia digital no supone solamente el dominio de los diferentes dispositivos y aplicaciones. El mundo digital es un nuevo hábitat en el que la infancia y la juventud viven cada vez más: en él aprenden, se relacionan, consumen, disfrutan de su tiempo libre. Con el objetivo de que el sistema educativo adopte el lugar que le corresponde en el cambio digital, se incluye la atención al desarrollo de la competencia digital de los y las estudiantes de todas las etapas educativas, tanto a través de contenidos específicos como en una perspectiva transversal, y haciendo hincapié en la brecha digital de género».

26 Tendríamos que plantearnos, por ejemplo, si se produce también segregación por razones socioeconómicas (Rey, 2021, 52-57). 
que tiene que ver con todo lo planteado en las páginas anteriores ${ }^{27}$. Es decir, con su papel de promoción de la igualdad sustancial, de baluarte ético especialmente en épocas de populismos y fundamentalismos y, en fin, de reequilibrio de las injusticias sociales que hacen que determinadas personas y colectivos queden en los márgenes ${ }^{28}$. Estos objetivos han de limitar necesariamente la libertad de enseñanza para que el derecho a una educación inclusiva sea efectivo en el marco de unas escuelas concebidas como espacios socializadores ${ }^{29}$, mixtos y coeducativos $^{30}$, implicados activamente en la superación de cualquier forma de discriminación —o sea, inclusivos ${ }^{31}$, como inclusiva debe ser la ciudadanía- y por tanto responsables principales en la efectividad de la igualdad entendida como principio directivo. Esa «norma revolucionaria que impone una reforma permanente del ordenamiento dirigido a su máxima actuación» (Ferrajoli, 2019, 15) y sin la que difícilmente alcanzaremos una «sociedad democrática avanzada».

27 En este sentido, por ejemplo, se ha abierto un más que necesario debate sobre cómo el principio de meritocracia incide en una concepción competitiva y nada igualitaria de nuestras sociedades: un mercado de oportunidades en el que, sin ir más lejos, desempeñan un papel crucial la Universidad. Todo ello en el marco de un análisis crítico de la igualdad de oportunidades en cuanto principio que se acomoda al modelo neoliberal pero que no tiene capacidad transformadora de la realidad en términos de justicia social (Sandel, 2020; Rendueles, 2020).

Ahora bien, todo ello sin obviar la carga desmesurada que con frecuencia soporta la enseñanza, a la que con frecuencia trasladamos la responsabilidad de resolver determinados problemas sociales que requieren respuestas múltiples y colectivas: «La educación ha llegado a convertirse en la única solución que somos capaces de imaginar para una asombrosa cantidad de desafíos y problemas colectivos. Se ha generalizado la tesis de que la educación es el único remedio para la crisis económica, el cambio climático, el sexismo, la delincuencia, la exclusión y todo lo demás. Una parte significativa del igualitarismo contemporáneo se ha zambullido con entusiasmo en esta especie de idealismo formativo» (Rendueles, 2020: 274).

29 Por ejemplo, «las medidas para combatir la segregación educativa limitan o comprimen la libertad de elección de centro escolar, pero es que este último derecho es tan limitable como otros y debe ponderarse con la prohibición de discriminación étnico/racial en relación con el derecho a una educación inclusiva de calidad» (Rey, 2019, 271).

30 Clara Souto (2018: 108) propone la reforma de los apdos. 1 y 2 de la CE en los siguientes términos: «1. Todas las personas tienen el derecho a la educación. La educación tendrá por objeto el pleno desarrollo de la personalidad humana sobre la base de los principios de igualdad, coeducación y tolerancia, y en el respeto a los valores superiores del ordenamiento jurídico y a los derechos fundamentales».

31 «La educación inclusiva forma parte del contenido esencial del derecho constitucional de educación y la segregación educativa, en cualquier ámbito, es una exclusión individual y grupal discriminatoria en los términos del art. 14 de la Constitución» (Rey, 2021, 122). 


\section{Bibliografía}

Aláez Corral, B. (2009a). El ideario educativo constitucional como fundamento de la exclusión de la educación diferenciada por razón de sexo de la financiación pública. Revista Española de Derecho Constitucional, 86, 31-69.

Aláez Corral, B. (2009b). Ideario educativo constitucional y respeto a las convicciones morales de los padres: a propósito de las sentencias del Tribunal Supremo sobre «Educación para la Ciudadanía». El Cronista del Estado Social y Democrático de Derecho, 5, 1-22.

Alcalá, P. (2020), Educación feminista. En A. H. Puleo (ed.). Ser feministas. Pensamiento y acción. (pp. 89-92). Madrid: Cátedra.

Báez Serrano, R. (2019). Hacia la consolidación de la constitucionalidad de la educación diferenciada. Revista de Derecho Político, 105, 251-278. Disponible en: https://doi.org/10.5944/rdp.105.2019.25274.

Ferrajoli, L. (2019). Manifiesto por la igualdad. Madrid: Trotta.

Gómez Fernández, I. (2019). Perspectiva feminista en la jurisprudencia reciente del Tribunal Constitucional de España. Revista Aranzadi Doctrinal, 11.

Guttman, A. (2001). La educación democrática. Una teoría politica de la educación. Madrid: Paidós.

Nuño Gómez, L. (2020). El derecho a la educación: estrategias patriarcales contra la genealogía femenina. Granada: Comares.

Pérez Royo, J. (2010). Curso de Derecho Constitucional. Madrid: Marcial Pons.

Rendueles, C. (2020). Contra la igualdad de oportunidades. Barcelona: Planeta.

Rey Martínez, F. (2019). Derecho antidiscriminatorio. Cizur Menor: Thomson Reuters, Aranzadi.

Rey Martínez, F. (2021). Segregación escolar en España. Marco teórico desde un enfoque de derechos fundamentales y principales ámbitos: socioeconómico, discapacidad, etnia y género. Madrid: Marcial Pons.

Rippon, G. (2020). El género y nuestros cerebros. La nueva neurociencia que rompe el mito del cerebro femenino. Barcelona: Galaxia Gutenberg.

Salazar Benítez, O. (2010). Cartografías de la igualdad. Ciudadanía e identidades en las democracias contemporáneas. Valencia: Tirant lo Blanch.

Salazar Benítez, O. (2016), Educación diferenciada por razón de sexo y derecho a la educación. Sobre la inconstitucionalidad de la reforma del artículo 84.3 de la Ley Orgánica de Educación. Revista Española de Derecho Constitucional, 106, 451-478.

Saldaña, N. (2010). Los estudios de género en los grados en Derecho: propuestas para un diseño curricular de la enseñanza del Derecho Constitucional con perspectiva de género en el Espacio Europeo de Educación Superior. Revista de Educación y Derecho, 3, 1-23.

Souto Galván, C. (2018). Artículo 27. En Y. Gómez Sánchez (coord.). Estudios sobre la reforma de la Constitución de 1978 en su cuarenta aniversario. (pp. 107-110). Cizur Menor: Thomson Reuters-Aranzadi.

Vidal Prado, C. (2017). El derecho a la educación en España. Bases constitucionales para el acuerdo y cuestiones controvertidas. Madrid: Marcial Pons. 